\title{
Geodetic imaging of the 2018 Killauea Volcano eruption and earthquake sequence: Implications for earthquake cycle monitoring and hazard mitigation of Kīlauea's south flank
}

\author{
BRIDGET SMITH-KONTER
}

University of Hawaii at Manoa, brkonter@hawaii.edu

The 2018 Kîlauea Volcano eruption and earthquake sequence provided an unprecedented opportunity to geodetically image volcanic and tectonic deformation in nearreal time. Observed every three days from May-August 2018 by the Sentinel-1 satellite, the 2018 Kilauea event was a exceptional chance to rapidly obtain, process, and deliver interferometric synthetic aperture radar (InSAR) data and products to the scientific community for improved hazard forecasting and rapid assessment of remote regions to help direct emergency response and recovery efforts. Additionally, these data provided critical insights into the evolving deformation of the 2018 Kîlauea Volcano eruption from several sources: (1) the April 30th collapse of Pu'u 'Ō'o crater, (2) the May 1 st dike intrusion, propagation, and subsequent contraction of the lower East Rift Zone that extended from $\mathrm{Pu}^{\prime} \mathrm{u}$ ' $\overline{\mathrm{O}}^{\prime} \overline{\mathrm{o}}$ to the Leilani Estates region, (3) the continuous deflation of Kỉlauea's summit region as large volumes of magma were withdrawn, and (4) the sprawling deformation from the May 4th $M_{w} 6.9$ Leilani Estates thrust earthquake along the south flank region. With respect to the latter, current interpretation of geological and geophysical observations from Kīlauea's south flank suggests that continuous creep, slow slip events, and major earthquakes are all occurring on the same fault plane. Integration of geodetic and seismic observations spanning the most recent sources of activity to those from several decades ago allow us to better understand earthquake phenomena, reconcile deformation rates, and quantify the processes that control fault stress and strain accumulation/transfer/release at Kīlauea. These activities, as well as continued geophysical monitoring, are major targets for advancing our understanding of earthquake hazards at Kỉlauea and for executing an optimal response when pending events strike. 